\title{
Small Airways in Idiopathic Pulmonary Fibrosis
}

\section{COMPARISON OF MORPHOLOGIC AND PHYSIOLOGIC OBSERVATIONS}

\author{
Jack D. Fulmer, William C. Roberts, Edwyna R. von Gal, \\ and Ronald G. Crystal \\ From the Pulmonary Branch and the Pathology Branch, National Heart, Lung, \\ and Blood Institute, National Institutes of Health, Bethesda, Maryland 20014
}

A B S T R A C T 18 patients with idiopathic pulmonary fibrosis were studied to determine if they had morphologic evidence of small airways disease and if physiologic testing could predict morphologic findings. In the presence of normal airway function by standard physiologic studies (forced expiratory volume in 1 s/forced vital capacity and airway resistance by plethysmography), dynamic compliance, maximum expiratory flow-volume curves, and maximum flowstatic recoil curves were measured to detect physiologic alterations consistent with small airways abnormalities. These physiologic data were then compared with estimates of small airways diameter made in lung biopsy specimens.

94\% (17 of 18) of the patients had peribronchiolar fibrosis or peribronchiolar inflammation or bronchiolitis. $67 \%$ (12 of 18) had an overall estimate of small airways diameter of "narrowed," whereas $33 \%$ (6 of 18) had airways that overall were "not narrowed." $59 \%$ (10 of 17) had frequency-dependent dynamic compliance, $50 \%$ (9 of 18) had abnormal maximum expiratory flow-volume curves, and 39\% (7 of 18) had abnormal maximum flow-static recoil curves. Comparisons between morphologic and physiologic data revealed a significant correlation between the results of dynamic compliance and the overall estimate of small airways diameter $(P=0.001)$, and the results of maximum flow-volume curves and the overall estimate of small airways diameter $(P=0.009)$; there was no significant correlation between the results of maximum flow-static recoil curves and the overall estimate of small airways diameter $(P=0.1)$.

The results of this study suggest that: $(a)$ idiopathic pulmonary fibrosis is a disease of small airways as

Reprint requests may be addressed to Dr. Fulmer, Room 6 N260, Bldg. 10, National Institutes of Health, Bethesda, Md. 20014.

Received for publication 13 October 1976 and in revised form 11 April 1977. well as alveoli; $(b)$ dynamic compliance and the maximum expiratory flow-volume curve can predict the overall status of small airways diameter in idiopathic pulmonary fibrosis; and $(c)$ whereas the maximum flowstatic recoil curve predicts the overall estimate of small airways diameter in most patients with this disease, it is the least sensitive of these three monitors of small airways.

\section{INTRODUCTION}

Idiopathic pulmonary fibrosis (IPF) ${ }^{1}$ is a well-defined subgroup of the fibrotic lung disorders, characterized by distinct clinical, radiographic, physiologic, and morphologic features $(1-16)$. These patients usually have exertional breathlessness, a diffuse interstitial infiltrate on chest $\mathrm{X}$ ray, decreased lung volumes, decreased diffusing capacity, and hypoxemia which worsens with exercise. Although the hypoxemia in IPF was initially thought to result from a diffusion barrier to oxygen (17), current data suggest that it mostly results from a ventilation-perfusion imbalance $(18,19)$.

In general, the most likely cause of hypoxemia secondary to a ventilation-perfusion imbalance is maldistribution of ventilation resulting either from airways disease or alterations in regional compliance or both. Because IPF has been considered to be a disease of alveoli and not of airways, maldistribution of ventilation in this disorder has previously been attributed to alterations in regional compliance (18). However, recent studies in disorders other than IPF (e.g. asthma)

\footnotetext{
${ }^{1}$ Abbreviations used in this paper: Cdyn, dynamic compliance; Cstat, static compliance; $\mathrm{D}_{\mathrm{Lco}}$, carbon dioxide diffusing capacity; $\mathrm{FEV}_{1} \%$, forced expiratory volume in $1 \mathrm{~s} /$ forced vital capacity; FRC, functional residual capacity; IPF, idiopathic pulmonary fibrosis; MEFV, maximum expiratory flow volume; MFSR, maximum flow static recoil; $\mathrm{P}_{\mathrm{L}}$, transpulmonary pressure; Pst, static transpulmonary pressure; Raw, airway resistance; $\mathrm{RV}$, residual volume; TLC, total lung capacity; VC, vital capacity; $\dot{\mathrm{V}}_{\max }$, maximum expiratory flow.
} 
have demonstrated that hypoxemia can result from the maldistribution of ventilation due to narrowing of small $(<2 \mathrm{~mm})$ airways, an obstruction which is not detected by standard physiologic studies $(20,21)$.

In light of these newer concepts of small airways disease, the present study was designed to: (a) evaluate the morphology of small airways in IPF; (b) determine if patients with IPF have physiologic alterations consistent with small airways disease; and $(c)$ attempt to correlate these morphologic and physiologic findings. To do so, we chose a group of patients with IPF who had normal airway function by standard physiologic studies and who had undergone lung biopsy within close proximity to a physiologic evaluation of small airways function. The results demonstrate that we must expand the concepts of IPF to consider it a disorder of small airways as well as alveoli.

\section{METHODS}

\section{Patient population}

Over an 18-mo period, 150 patients were referred to the Pulmonary Branch, National Heart, Lung, and Blood Institute for evaluation of interstitial lung disease. From this group, patients were determined to have IPF if they fit the following criteria (14-16).

Clinical. History of exertional breathlessness; no history of exposure to inorganic, organic, gaseous, physical, or pharmacologic agents known to cause pulmonary fibrosis; no history suggestive of an allergic pulmonary disorder; no history of chronic pulmonary infection; and no historical or physical evidence of left ventricular failure. All patients underwent fiberoptic bronchoscopy (B2F, Olympus Corporation of America, New Hyde Park, N. Y.) and were demonstrated to have normal airways within limits of the procedure.

Roentgenographic. The presence of a diffuse infiltrative pattern (reticular, reticulonodular, or ground glass) on a routine posterior-anterior chest film and no evidence of left ventricular disease.

Physiologic. Reduced lung volumes or reduced diffusing capacity or both; mild to moderate hypoxemia at rest which worsened with exercise, and a static volume-pressure curve consistent with fibrotic disease (see below for physiologic methods).

Morphologic. Lung biopsy showing varying degrees of alveolar septal fibrosis and inflammation with interstitial and intra-alveolar inflammatory cells (predominantly mononuclear cells, but often accompanied by neutrophils and eosinophils); no granuloma, no vasculitis, no evidence of inorganic material by polarized light microscopy, and negative cultures for bacteria and fungi.

Patients were included in the current study if they met all of the diagnostic criteria for IPF, and had no evidence of airways disease by standard criteria (forced expiratory volume in $1 \mathrm{~s} /$ forced vital capacity and airway resistance). In addition, they had to have had a recent lung biopsy demonstrating airways of $<2 \mathrm{~mm}$ in diameter and be able to participate in measurement of at least two of three monitors of small airways (see below).

From the initial group of 150 patients, 50 had the diagnosis of IPF and 18 of these fit all of the criteria to be included in this study. Patients who were excluded from the study were done so largely because of failure to have a recent biopsy or because of advanced disease and inability to participate in physiologic studies. $15 \mathrm{had}$ no evidence of a collagen vascular disease, two (M. C., V. J.) had rheumatoid arthritis, and one (O. N.) had an overlap connective tissue syndrome. Eight patients had open lung biopsy at our institution with physiologic testing performed within $2 \mathrm{wk}$ before biopsy. The remaining 10 patients had lung biopsies performed at an outside institution with physiologic testing performed at our institution 3-18 mo (average $4 \mathrm{mo}$ ) after biopsy.

\section{Airway morphology}

Morphological observations were made by one of us (W. C. R.) without knowledge of the results of the physiological testing. All observations were made on surgical specimens fixed in formalin, processed in alcohols and xylene, imbedded in paraffin, sectioned at $6 \mu \mathrm{m}$ intervals, and then stained with hematoxylin and eosin. Serial sections were evaluated whenever possible. Airways of $2-\mathrm{mm}$ diameter or less which had nearly perpendicular cuts were selected for evaluation. Each biopsy contained an average of $7.7 \pm 0.7^{2}$ airways which were suitable for study.

The following histologic features of small airways were noted if present: peribronchiolar fibrosis, peribronchiolar inflammation, and bronchiolitis. In addition, the diameters of small airways were graded as to whether they were normal, narrowed, or dilated by the following criteria: $(a)$ comparing the diameter of the bronchiolar lumen to the diameter of the lumen of the accompanying pulmonary artery (the bronchiolar lumen should be as large or larger than the lumen of the artery); (b) comparing the diameter of the bronchiolar lumen in the biopsy to the bronchiolar lumen of noninflated normal lung with comparable sized bronchioles and pulmonary arteries; and $(c)$ comparing the thickness of the bronchiolar wall to the thickness of the wall of comparably sized airways of noninflated normal lungs. Changes in pulmonary artery diameter associated with pulmonary hypertension were quantitated to adjust lumen diameter to a normal size and prevent over estimation of airway diameter. If an airway was normal or dilated, but on serial section was shown to be narrowed at some point, it was graded as narrowed.

To facilitate comparison of morphologic and physiologic studies, an overall estimate of the diameter of the small airways in each biopsy was made using the following criteria: if $60 \%$ or more airways in the biopsy were narrowed, airways diameter was considered "narrowed," independent of status of the other airways; if $70 \%$ or more of the airways in the biopsy were normal or dilated (i.e. $30 \%$ or less were narrowed), airways diameter was considered "not narrowed," independent of the status of the other airways. If $31-59 \%$ of the airways in the biopsy were narrowed, the morphologic data for that patient were not used for statistical comparison with the physiologic data.

\section{Lung volumes, timed expiratory maneuver, and diffusing capacity}

Lung volumes, timed expiratory maneuver and diffusing capacity were measured on a computerized lung analyzer (Warren E. Collins, Inc., Braintree, Mass.). Vital capacity (VC), forced vital capacity, forced expiratory volume in $1 \mathrm{~s}$, and inspiratory capacity were done in the standing position. Functional residual capacity (FRC) was done in the sitting

\footnotetext{
${ }^{2}$ All data will be presented as mean \pm SEM.
} 
position utilizing a closed circuit helium equilibration technique (22). Expiratory reserve volume was subtracted from FRC to obtain residual volume (RV) and VC was added to RV to obtain observed total lung capacity (TLC). Predicted values for $\mathrm{VC}$, forced expiratory volume in $1 \mathrm{~s}$, and forced expiratory volume in $1 \mathrm{~s}$ /forced vital capacity $\left(\mathrm{FEV}_{1} \%\right)$ were obtained from the data of Morris et al. (23). Predicted FRC and $\mathrm{RV}$ were obtained from the normals of Goldman and Becklake (24). Predicted TLC was obtained by adding predicted VC to predicted RV. The lower limit of lung volumes was considered to be $-20 \%$ of the predicted value. The lower limit for $\mathrm{FEV}_{1} \%$ was considered to be equal to the predicted $\mathrm{FEV}_{1} \%-5 \%(25)$.

Single-breath carbon monoxide diffusing capacity $\left(\mathrm{D}_{\mathrm{LCO}}\right)$ was performed by the method of Ogilvie et al. (26). The program was modified so that alveolar volume was determined by a single-breath helium dilutional technique. Alveolar gas was quantitated after absorption of $\mathrm{CO}_{2}$; gas concentrations were then adjusted by $6 \%$ for $\mathrm{CO}_{2}$ removal $(6 \%$ is the usual alveolar $\mathrm{CO}_{2}$ concentration). The results were compared to the predicted values of Gaensler and Wright (27).

\section{Airway resistance}

Airway resistance (Raw) was determined by modification of the method of Dubois et al. (28) using a constant volume plethysmograph (Warren E. Collins, Inc.). Statham differential transducers (Pm 6 and 15, Gould, Inc., Oxnard, Calif.) were interfaced with carrier amplifiers (model $8805 \mathrm{~B}$, HewlettPackard Co., Palo Alto, Calif.). Flow was measured with a heated number 3 Fleisch pneumotachograph (Medical Products, Blue Bell, Pa.). All transducers had a frequency response within $\pm 5 \%$ up to 6 cycles/s. The Fleisch pneumotachograph was linear from 0.1-6 liters/s. Data were recorded on a storage oscilloscope (Tektronix, Inc., Beaverton, Oreg.) and either traced directly on cellulose paper or photographed. Raw was measured by the slope of where the loop crossed a flow of 1 liter/s. The resistance of the pneumotachograph, shutter assembly, and mouth piece $(0.35 \mathrm{~cm}$ $\mathrm{H}_{2} \mathrm{O} /$ liter per s) was subtracted from the total Raw. Normal Raw was considered to be $₹ 2.5 \mathrm{~cm} \mathrm{H}_{2} \mathrm{O} /$ liter per s (28).

\section{Maximum expiratory flow-volume relationship}

The relationship between maximum expiratory flow and volume (MEFV) was determined in the sitting position utilizing a wedge spirometer (570, Med-Science Electronics, Inc., St. Louis, Mo.) connected to a rapidly responding (1,500 in $/ \mathrm{s}^{2}$ ) XY recorder (model 7046A, Hewlett-Packard Co.). The apparatus was calibrated electronically and checked manually utilizing a 1-liter syringe (Warren E. Collins, Inc.) and a 010-liter/s flow meter (Vol-O-Flow, National Institute Laboratories Inc., Rockville, Md.). Calibration of flow was accomplished by incorporating a low resistance three-way valve (Warren E. Collins, Inc.) between a flow generator (vacuum cleaner) and flow meter and spirometer so that flow rate and time could be controlled; flow was linear from 0.1 to 10 liters/s.

A minimum of three MEFV curves were performed at each sitting and most patients had four to six curves done during their evaluation. The two most reproducible curves with the best flow rates and volumes within $\pm 5 \%$ of VC (as quantitated by standard water spirometry) were accepted. Final MEFV curves were constructed from these data using the highest flow rates at all volumes.

The final MEFV data were analyzed by three methods: (a) with flow (liters/second) plotted against volume (observed VC); (b) with flow (liters/second) plotted against volume (percent observed TLC); and (c) with flow divided by observed TLC (liters/second per liter) plotted against volume (percent observed VC remaining). Because of the wide variation in lung volumes in the patient population, method $c$ was found to be most useful; these data were compared to the normal values of Gelb et al. (29).

\section{Static compliance, dynamic compliance, and isovolume pressure-flow curves}

These data were obtained in the sitting position utilizing a wedge spirometer for quantitation of volume and flow rates. Transpulmonary pressure $\left(\mathrm{P}_{\mathrm{L}}\right)$ was measured as the difference between mouth and esophageal pressure utilizing a Sanborn 268-B differential strain gauge and carrier preamplifier (Hewlett-Packard Co.). Volume, flow, and $\mathrm{P}_{\mathrm{L}}$ signals were recorded on a Brush model 480, eight channel universal recorder (Gould, Inc.). The esophageal pressure signal was transmitted by a $10 \mathrm{~cm}$, thin-walled, latex balloon (Young Rubber Co., Trenton, N.J.) positioned in the lower third of the esophagus by first passing it into the stomach and observing for a positive defection, then withdrawing the balloon approximately 10 $\mathrm{cm}$ so that the pressure signal was maximum and artifact free. Balloon volume was corrected by the methods of Milic-Emili et al. (30) or Lemen et al. (31); the latter technique was simpler and closely agrees with the former.

The wedge spirometer was calibrated electronically and checked manually utilizing a 1-liter syringe and a $0-10$ liter/s flow meter. Using a sine wave generator, the frequency response of the spirometer was $\pm 5 \%$ at 6 cycles/s and flow was linear from 0.1 to 10 liters/s. The Sanborn 268-B differential strain gauge was linear between $0-100 \mathrm{~cm} \mathrm{H}_{2} \mathrm{O}$ and had a frequency response which was $\pm 5 \%$ at 6 cycles/s. Evaluation of phase lag between signals of flow, volume, and esophageal balloon pressure was performed by inserting the balloon inside the wedge spirometer and applying a sine wave (using a $500-\mathrm{ml}$ pump) to the system. These signals were in phase $\left(<5^{\circ}\right.$ shift $)$ up to 3 cycles/s.

A constant volume history was assured by having the patient hyperventilate and then inspire to TLC three times (32). Static transpulmonary pressure (Pst) was measured at TLC and during deflation as the pressure difference between mouth and esophageal pressure with glottis open and flow being interrupted by a solenoid-operated shutter.

Static volume-pressure curves were constructed utilizing a mean of four deflation maneuvers with $12-14$ points per maneuver. Volume was converted to body temperature and pressure saturated and required to be $\pm 5 \%$ of $\mathrm{VC}$ (as recorded on standard spirometry). Because of the marked variability of Pst below 50\% observed TLC, static volume-pressure curves were constructed from TLC to $50 \%$ observed TLC. Volume was expressed both as a percentage of observed and predicted TLC and compared to the predicted data of Turner et al. (32).

Data for generation of isovolume pressure-flow curves were obtained by having the patient exhale from TLC to RV at varying efforts from maximum flow to 0.5 liter/s. From simultaneously recorded flow, volume, and $\mathrm{P}_{\mathrm{L}}$ data, isovolume pressure-flow curves were constructed at 70,50 , and $30 \% \mathrm{VC}$ according to the method of Hyatt et al. (33).

Dynamic compliance (Cdyn) was measured by having the patient first hyperventilate, inspire to TLC three times, and then breathe at a constant tidal volume at increasing frequencies up to 100 breaths $/ \mathrm{min}$. Flow, volume, and $\mathrm{P}_{\mathrm{L}}$ were simultaneously recorded while a constant resting end expiratory point and resting end inspiratory point were maintained by having the patient observe his breathing pattern (volume) on a time base oscilloscope. For each frequency, Cdyn was calculated by dividing the volume change by the change in pressure at points of zero flow over 10 or more breaths and 
averaging the results. Cdyn was expressed as a percentage of initial Cdyn (Cdyn/initial Cdyn) and plotted against respiratory frequency. A frequency dependent decrease in Cdyn/ initial Cdyn of $>20 \%$ was considered to be abnormal $(34,35)$.

To determine the effect of bronchodilators on Cdyn, these maneuvers were repeated immediately after $0.5 \mathrm{ml}$ of $1 \%$ isoetherine was administered as an aerosol inhalant.

\section{Maximum flow-static recoil relationship}

The relationship between maximum flow and static recoil (MFSR) was determined by plotting maximum expiratory flow $\left(\dot{\mathrm{V}}_{\text {max }} ;\right.$ obtained from the MEFV curve from 80 to $50 \%$ observed TLC) against Pst (derived from the static volume-pressure curve) at the same lung volumes (36). These data were also plotted utilizing $\dot{\mathrm{V}}_{\max }$ and Pst expressed as percentage of predicted lung volume. Predicted MFSR curves were obtained by plotting $\dot{\mathrm{V}}_{\max }$ predicted by the data of Cherniack and Raber (37) against Pst at the same lung volume predicted by the data of Turner et al. (32). The prediction curves were grouped by age range from 25 to $45 \mathrm{yr}$ and greater than $45 \mathrm{yr}$. These curves compare favorably to the normal curves of Mead et al. (36) and Ostrow and Cherniack. (38).

\section{Statistical analysis of data}

Three statistical methods were used for data analysis: Spearman rank correlation, two-tailed Student's $t$-test, and Fisher's exact test. To facilitate discussion of the analysis, the data were grouped as follows: "clinical data" include age, sex, duration of symptoms, smoking history, and drug therapy; "standard physiologic studies" include VC, FRC, TLC, RV/TLC, and $D_{\text {LCo }}$; "physiologic monitors of small airways" include Cdyn, MEFV curves, and MFSR curves; and "overall estimate of small airways diameter" refers to the rating ("narrowed" or "not narrowed") given to each biopsy as defined by the criteria listed above.

The choice of a statistical method for comparisons among clinical, physiologic, and morphologic data was dictated by the form of the data. Spearman rank correlation (39) was used when one variable was ranked and the other variable was ranked or continuous. The two-tailed Student's $t$ test (40) was used when the mean values for a continuous variable could be determined for each of two ranked groups. Fisher's exact (41) test was used when both variables could be ranked in two categories and a contingency table could be constructed. In certain comparisons, more than one statistical comparison was used. A standard Pearson correlation was not used because it assumes a normal distribution for both variables and in all comparisons made at least one variable was ranked.

Utilizing these criteria, the following statistical comparisons were made:

(a) Spearman rank correlation of clinical data vs. overall estimate of small airways diameter; standard physiologic studies vs. overall estimate of small airways diameter; clinical data vs. physiologic monitors of small airways; and standard physiologic studies vs. physiologic monitors of small airways; (b) two-tailed Student's $t$ test of standard physiologic studies vs. overall estimate of small airways diameter; and (c) Fisher's exact test of physiologic monitors of small airways vs. overall estimate of small airways diameter; and RV/TLC, MEFV curves and MFSR curves vs. Cdyn.

\section{RESULTS}

Clinical data. The 18 study patients ranged in age from 27 to $67 \mathrm{yr}, 12$ were male and 6 were female (Táble I). Six patients never smoked; an additional three were light cigarette smokers $(<10$ pack yr) and one was a cigar smoker. The remaining eight patients were either moderate (10-25 pack yr) or heavy smokers ( $>25$ pack yr) and none had a history of sputum production. The duration of symptoms (before study at National Institutes of Health) ranged from 0.5 to 10 $\mathrm{yr}$, but was $\leq 2 \mathrm{yr}$ in all but one patient (W. L.). Eight patients were taking prednisone at the time of evaluation; one was taking phenylbutazone, and none was taking sympathomimetic agents or xanthines.

Morphologic evaluation of small airways in IPF. A total of 138 small airways were suitable for evaluation in the lung biopsies of the 18 patients (Table II). The most frequently observed morphologic abnormality was peribronchiolar fibrosis, either alone or together with peribronchiolar inflammation and bronchiolitis (Fig. 1). No airway was seen with bronchiolitis alone. Only one patient (W. L. S.) had completely normal airways.

Each biopsy was graded an average of three times. Using the grading criteria for airway diameter, the mean intraobserver coefficient of variation was 9.1. $\pm 0.2 \%$; the mean interobserver error was $10 \%$. Of the total airways evaluated, $19 \%$ were of normal diameter, $27 \%$ were dilated, and $54 \%$ were narrowed (Table II). The dominant histologic abnormality accompanying narrowed airways was peribronchiolar fibrosis with infolding and stenosis (Fig. $1 \mathrm{~B}$ ); seen less frequently was peribronchiolar fibrosis or inflammation and bronchiolitis (Fig. 1 C). The presence of histologic abnormalities of small airways did not necessarily mean the airway would be narrowed; peribronchiolar inflammation and peribronchiolar fibrosis were associated with airways that were of normal diameter (Fig. 1 A) or dilated (Fig. $1 \mathrm{D}$ ).

Using the criteria listed in Methods, overall estimates of small airways diameter revealed that 12 of the 18 patients $(67 \%)$ had "narrowed" airways (i.e. in these patients, $60 \%$ or more of the small airways evaluated were narrowed) and the remaining 6 patients (33\%) had "not narrowed" airways (i.e. in these patients, $70 \%$ or more of the airways evaluated were normal or dilated).

Standard physiologic studies and routine monitors of airways. The lung volumes were variable in the 18 patients with IPF, but the mean predicted values were significantly reduced (Table III). Although patients with histologically proven IPF are generally considered to have reduced volumes, one (E. B.) had a TLC within the normal range. Likewise, although almost all of the patients had a reduced $D_{L c o}$ (mean $52.7 \%$ predicted), one patient (B. T.) had a $\mathrm{D}_{\mathrm{Lco}}$ within the normal range. Thus, all of the patients had either a reduced TLC or $D_{L C O}$, and $89 \%$ had both. The average RV/TLC was $31.8 \%$; 10 patients had normal RV/TLC ( $<30 \%$ observed). 
TABLE I

Clinical Data of 18 Patients with IPF

\begin{tabular}{|c|c|c|c|c|c|c|c|}
\hline Patient & Age & Sex & Height & Weight & $\begin{array}{l}\text { Smoking } \\
\text { history* }\end{array}$ & $\begin{array}{l}\text { Duration of } \\
\text { symptoms }\end{array}$ & Drugs $\downarrow$ \\
\hline & $y r$ & & $\mathrm{~cm}$ & $k g$ & & $y r$ & \\
\hline E. B. & 48 & $\mathbf{M}$ & 195 & 100 & Heavy & 1.5 & None \\
\hline M. C. & 57 & $\mathrm{~F}$ & 158 & 76 & Nonsmoker & 0.5 & Phenylbutazone \\
\hline R. C. & 66 & $\mathbf{M}$ & 172 & 68 & Nonsmoker & 0.5 & Prednisone \\
\hline N. C. & 27 & $\mathbf{M}$ & 174 & 53 & Light & 2.0 & Prednisone \\
\hline A. D. & 67 & $\mathbf{M}$ & 164 & 65 & Medium $\S$ & 0.5 & Prednisone \\
\hline G. F. & 51 & $\mathbf{M}$ & 183 & 76 & Medium $\S$ & 2.0 & Prednisone \\
\hline A. $\mathrm{H}$. & 26 & $\mathrm{~F}$ & 178 & 62 & Light $\oint$ & 2.0 & None \\
\hline W. H. & 41 & $\mathbf{M}$ & 183 & 84 & Light $\oint$ & 2.0 & None \\
\hline V. J. & 27 & $\mathrm{~F}$ & 162 & 48 & Nonsmoker & 0.5 & None \\
\hline W. L. & 67 & $\mathbf{M}$ & 179 & 86 & Heavy $\S$ & 10.0 & None \\
\hline O. N. & 27 & $\mathrm{~F}$ & 171 & 63 & Nonsmoker & 1.5 & Prednisone \\
\hline P. R. & 31 & $\mathrm{~F}$ & 175 & 88 & Medium & 0.5 & Prednisone \\
\hline J. C. S. & 61 & $\mathbf{M}$ & 172 & 77 & Heavy $\S$ & 1.5 & None \\
\hline W. E. S. & 66 & $\mathbf{M}$ & 173 & 85 & Cigars $\S$ & 1.0 & None \\
\hline R. S. & 52 & $\mathbf{M}$ & 186 & 66 & Nonsmoker & 2.0 & Prednisone \\
\hline J. K. S. & 46 & $\mathbf{M}$ & 182 & 80 & Medium§ & 2.0 & Prednisone \\
\hline W. L. S. & 58 & $\mathbf{M}$ & 171 & 72 & Medium $\S$ & 1.0 & None \\
\hline B. T. & 47 & $\mathbf{F}$ & 163 & 83 & Nonsmoker & 0.5 & None \\
\hline Mean \pm SEM & $48.1 \pm 3.6$ & & $174.5 \pm 2.2$ & $74.6 \pm 3.1$ & & $1.7 \pm 0.5$ & \\
\hline
\end{tabular}

* Light, <10 pack-yr; moderate, 10-25 pack-yr; heavy, >25 pack-yr.

\$ Only anti-inflammatory agents are listed; none of the patients was taking xanthines or sympathomimetics. $\S$ Stopped smoking $>6$ mo before study.

Routine monitors of airways $\left(\mathrm{FEV}_{1} \%\right.$, Raw) were normal in all patients tested. Four patients (G. F., W. L., J. K. S., R. S.) were unable to perform the necessary maneuvers to measure Raw because of marked resting breathlessness.

Volume-pressure relationship. Most patients exhibited increased elastic recoil at lung volumes above FRC with a shift of the volume-pressure curve downward and to the right when volume was expressed as a percentage of predicted TLC (Fig. 2). One patient (E. B.) had a borderline shift in the volume-pressure curve to the left of the predicted normal curve for his age. When volume was expressed as a percentage of measured TLC (Fig. 3), five patients (A. H., P. R., G. F., R. C., W. L.) had curves which were similar to normal except at high lung volumes.

Physiologic monitors of small airways. Cdyn, performed in 17 patients, was frequency independent in 7 and frequency dependent in 10 (Fig. 4). Three patients (G. F., P., R., and B. T.) exhibited Cdyn which was less frequency dependent after nebulized bronchodilators. In no case did the use of bronchodilators cause the Cdyn to become independent of frequency (data not shown).

Nine patients had abnormal MEFV curves with reduced flows at low lung volumes and nine had normal to increased flows at all lung volumes (Fig. 5). All three methods of analysis of the MEFV data (see Methods) give comparable results.

Seven patients had reduced flow rates for a given $P_{s t}$ with a shift of the MFSR curve to the right of the normal range. The remaining 11 patients had normal to increased flow rates for a given $P_{s t}$ (Fig. 6). Both methods of analysis (see Methods) gave comparable results.

Obtaining meaningful MEFV and MFSR curves depends upon achieving maximum flow. To verify that maximum flow was achieved in these studies, isovolume pressure-flow curves were constructed. 15 patients achieved maximum flow and effort independence at $50 \%$ VC (data not shown). The remaining three patients (M. C., G. F., W. E. S.) were not able to perform the necessary maneuvers to construct isovolume pressureflow curves because of breathlessness and inability to perform sustained expiratory maneuvers at variable flow rates.

Comparison of clinical, physiologic, and morphologic studies. Of the 17 patients $^{3}$ whose clinical and physiologic data were used for statistical comparisons

\footnotetext{
${ }^{3}$ One patient (R. C.) was excluded from the statistical comparisons with the overall estimate of small airway diameter because the lung biopsy was a drill biopsy which contained only one airway.
} 
TABLE II

Morphologic Evaluation of Small Airways in Lung Biopsy Specimens of 18 Patients with IPF

\begin{tabular}{|c|c|c|c|c|c|c|c|c|c|}
\hline \multirow[b]{3}{*}{ Patient } & \multirow{3}{*}{$\begin{array}{l}\text { Biopsy } \\
\text { site** }^{*}\end{array}$} & \multirow{3}{*}{$\begin{array}{c}\text { Number } \\
\text { of airways } \\
\text { examined }\end{array}$} & \multicolumn{3}{|c|}{ Histology $\ddagger$} & & & & \multirow{3}{*}{$\begin{array}{c}\text { Overall estimate } \\
\text { of small airway } \\
\text { diameter } \S\end{array}$} \\
\hline & & & $\begin{array}{c}\text { Peri- } \\
\text { bronchi- }\end{array}$ & $\begin{array}{c}\text { Peri- } \\
\text { bronchi- }\end{array}$ & & \multicolumn{3}{|c|}{ Small airway diameter } & \\
\hline & & & & flammation & $\begin{array}{l}\text { Donchn- } \\
\text { olitis }\end{array}$ & Normal & Dilated & Narrowed & \\
\hline & & & & & & & Number (\%) & & \\
\hline E. B. & LUL & 6 & + & 0 & 0 & $2 \quad(33)$ & $0 \quad(0)$ & $4 \quad(67)$ & Narrowed \\
\hline M. C. & LLL & 8 & + & + & 0 & $\begin{array}{ll}0 & (0)\end{array}$ & $1(13)$ & $7 \quad(87)$ & Narrowed \\
\hline R. C. & RLL & 1 & 0 & + & 0 & $\begin{array}{ll}0 & (0)\end{array}$ & $0 \quad(0)$ & $1(100)$ & Narrowed \\
\hline N. C. & LLL & 6 & + & + & + & $\begin{array}{ll}0 & (0)\end{array}$ & $2(33)$ & $4 \quad(67)$ & Narrowed \\
\hline A. D. & LLL & 11 & + & 0 & 0 & $1 \quad(9)$ & $7(63)$ & $3 \quad(27)$ & Not narrowed \\
\hline G. F. & LLL & 2 & + & 0 & 0 & $\begin{array}{ll}0 & (0)\end{array}$ & $0 \quad(0)$ & $2(100)$ & Narrowed \\
\hline A. $\mathrm{H}$. & LUL & 10 & + & 0 & 0 & $1 \quad(10)$ & $0 \quad(0)$ & $9 \quad(90)$ & Narrowed \\
\hline W. H. & $\begin{array}{l}\text { LLL } \\
\text { LUL }\end{array}$ & 10 & + & 0 & 0 & $7 \quad(70)$ & $0 \quad(0)$ & $3 \quad(30)$ & Not narrowed \\
\hline V. J. & RLL & 5 & 0 & + & 0 & $3 \quad(60)$ & $1(20)$ & $1 \quad(20)$ & Not narrowed \\
\hline W. L. & RLL & 9 & + & + & + & $1 \quad(11)$ & $2(22)$ & $6 \quad(67)$ & Narrowed \\
\hline O. N. & LUL & 9 & 0 & + & 0 & $1 \quad(11)$ & $6(67)$ & $2 \quad(22)$ & Not narrowed \\
\hline P. R. & LLL & 7 & + & + & + & $2 \quad(29)$ & $0 \quad(0)$ & $5 \quad(71)$ & Narrowed \\
\hline J. C. S. & LLL & 6 & + & 0 & 0 & $2 \quad(33)$ & $\begin{array}{ll}0 & (0)\end{array}$ & $4 \quad(67)$ & Narrowed \\
\hline W. E. S. & $\begin{array}{l}\text { RUL } \\
\text { RLL } \\
\text { RML }\end{array}$ & 10 & + & 0 & 0 & $\begin{array}{ll}0 & (0)\end{array}$ & $4(40)$ & $6 \quad(60)$ & Narrowed \\
\hline R. $S$. & RLL & 10 & + & 0 & 0 & $1 \quad(10)$ & $2(20)$ & $7 \quad(70)$ & Narrowed \\
\hline J. K. S. & LLL & 12 & + & 0 & 0 & $\begin{array}{ll}0 & (0)\end{array}$ & $10(83)$ & $2 \quad(17)$ & Not narrowed \\
\hline W. L. S. & RLL & 5 & 0 & 0 & 0 & $5(100)$ & $0 \quad(0)$ & $0 \quad(0)$ & Not narrowed \\
\hline B. $\mathrm{T}$. & LLL & 11 & 0 & + & + & $1 \quad(9)$ & $1 \quad(9)$ & $9 \quad(82)$ & Narrowed \\
\hline Total & & 138 & & & & $27 \quad(19)^{\prime \prime}$ & $36(27)^{\| \prime}$ & $75 \quad(54)^{\prime \prime}$ & \\
\hline
\end{tabular}

* LUL, left upper lobe; LLL, left lower lobe; RUL, right upper lobe; RML, right middle lobe; RLL, right lower lobe.

$\ddagger+$, present; 0 , not present.

$\$$ The overall estimate of small airway diameter was narrowed if $\geq 60 \%$ of the airways in the biopsy were narrowed, independent of the status (normal or dilated) of the other airways; the overall estimate of small airway diameter was not narrowed if $\leq 30 \%$ of the airways were narrowed, independent of the status (normal or dilated) of the other airways; if $31-59 \%$ of the airways were narrowed, the morphologic data was not used for statistical comparisons with the physiologic data. Patient R. C. had a needle biopsy with only one airway present; this data was not used for statistical comparisons.

" Percent total.

FIGURE 1 Examples of small airways in open lung biopsies of patients with IPF. A. Small airway of normal diameter in a 27-yr-old female (V. J.) demonstrating peribronchiolar inflammation $(\times 130)$. B. Narrowed small airway in a 26-yr-old female (A. H.) demonstrating peribronchiolar fibrosis with infolding and stenosis $(\times 220)$. C. Narrowed small airway in a 47yr-old female (B. T.) demonstrating peribronchiolar inflammation and bronchiolitis $(\times 130)$. $D$. Dilated small airway in a 67-yr-old male (A. D.) demonstrating peribronchiolar fibrosis $(\times 80)$. All sections were stained with hematoxylin and eosin. 

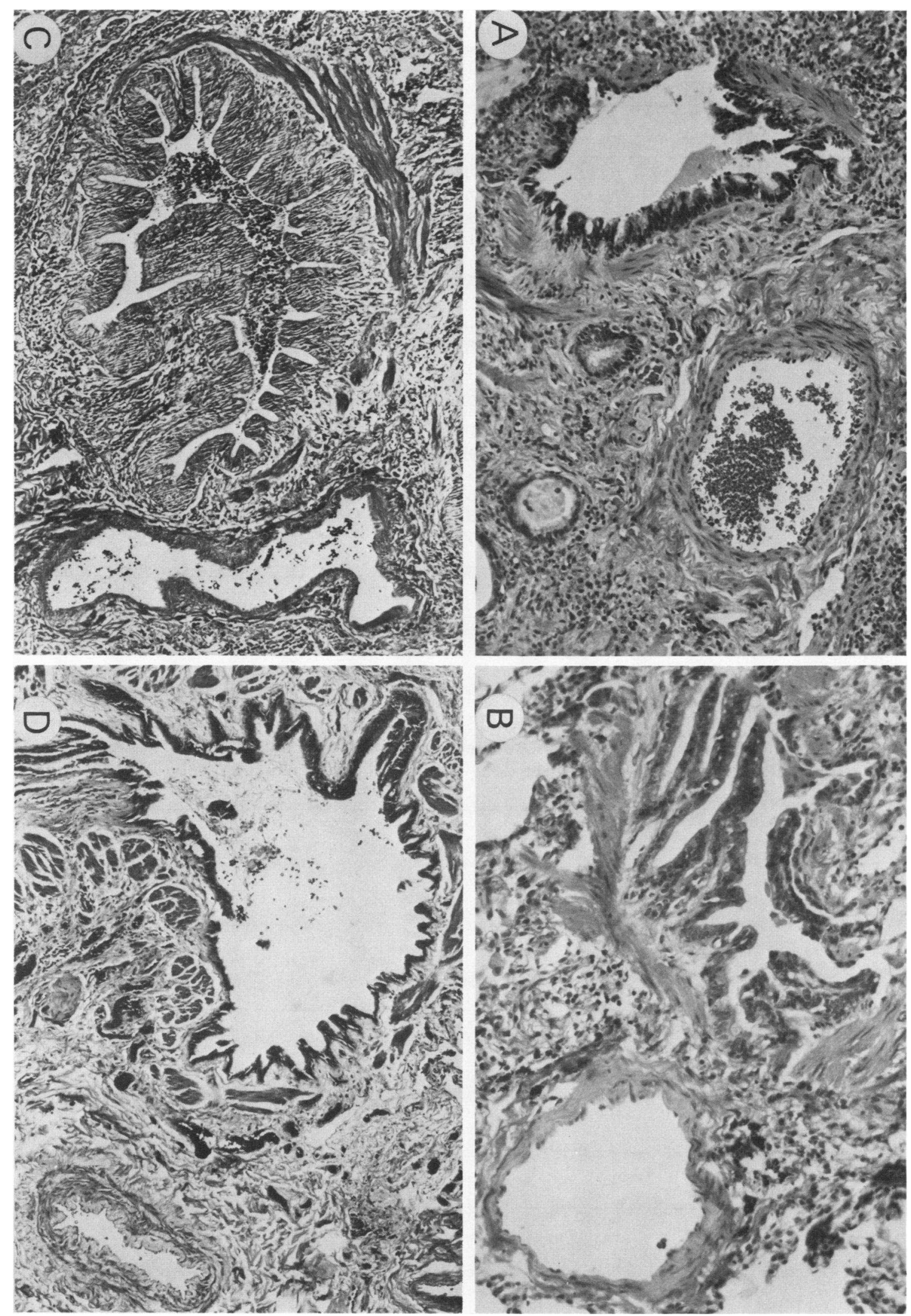
TABLE III

Standard Physiologic Studies of 18 Patients with IPF

\begin{tabular}{|c|c|c|c|c|c|c|c|c|c|c|c|c|}
\hline \multirow[b]{2}{*}{ Patient } & \multicolumn{2}{|c|}{ VC } & \multicolumn{2}{|c|}{ FRC } & \multicolumn{2}{|c|}{ TLC } & \multirow{2}{*}{$\begin{array}{c}\text { RVI } \\
\text { TLC } \\
\% \text { Ob- } \\
\text { served }\end{array}$} & \multicolumn{2}{|c|}{ Diffusing capacity* } & \multicolumn{2}{|c|}{$\mathrm{FEV}_{1} \%$} & \multirow{2}{*}{$\begin{array}{c}\text { Raw } \\
\mathrm{cm}_{2} \mathrm{O} / \\
\text { liter/s }\end{array}$} \\
\hline & Liters & $\begin{array}{l}\% \text { Pre- } \\
\text { dicted }\end{array}$ & Liters & $\begin{array}{l}\% \text { Pre- } \\
\text { dicted }\end{array}$ & Liters & $\begin{array}{l}\% \text { Pre- } \\
\text { dicted }\end{array}$ & & $\begin{array}{c}\mathrm{ml} \mathrm{CO} / \mathrm{mm} \\
\mathrm{Hg} / \mathrm{min}\end{array}$ & $\begin{array}{l}\% \text { Pre- } \\
\text { dicted }\end{array}$ & $\begin{array}{l}\% \text { Ob- } \\
\text { served }\end{array}$ & $\begin{array}{l}\% \text { Pre- } \\
\text { dicted }\end{array}$ & \\
\hline E. B. & 4.84 & 83 & 3.53 & 73 & 7.17 & 86 & 31 & 16.3 & 48 & 72 & 96 & 1.16 \\
\hline M. C. & 2.02 & 73 & 1.25 & 60 & 2.81 & 70 & 28 & 11.1 & 53 & 83 & 104 & 1.80 \\
\hline R. C. & 2.98 & 71 & 2.14 & 60 & 4.17 & 64 & 28 & 8.9 & 42 & 78 & 109 & 2.38 \\
\hline N. C. & 1.50 & 28 & 2.11 & 60 & 3.10 & 44 & 52 & 17.3 & 74 & 90 & 112 & 2.50 \\
\hline A. D. & 2.19 & 59 & 1.85 & 63 & 3.52 & 61 & 37 & 11.8 & 49 & 86 & 122 & 1.60 \\
\hline G. F. & 3.56 & 71 & 2.71 & 65 & 5.33 & 71 & 31 & 9.4 & 33 & 70 & 98 & ND $\ddagger$ \\
\hline A. $\mathrm{H}$. & 3.46 & 75 & 2.73 & 76 & 4.81 & 72 & 29 & 17.2 & 66 & 76 & 97 & 0.68 \\
\hline W. H. & 2.85 & 50 & 1.93 & 43 & 3.66 & 46 & 25 & 12.6 & 52 & 83 & 113 & 0.99 \\
\hline V. J. & 1.95 & 50 & 1.65 & 60 & 2.71 & 50 & 27 & 12.7 & 71 & 93 & 114 & 1.28 \\
\hline W. L. & 2.90 & 65 & 2.43 & 61 & 4.35 & 62 & 33 & 7.0 & 31 & 74 & 109 & ND $\ddagger$ \\
\hline O. N. & 1.86 & 45 & 1.73 & 54 & 2.62 & 43 & 29 & 9.5 & 57 & 98 & 125 & 2.12 \\
\hline P. R. & 2.55 & 60 & 2.76 & 81 & 4.24 & 67 & 47 & 11.5 & 47 & 81 & 102 & 1.68 \\
\hline J. C. S. & 2.34 & 55 & 1.42 & 55 & 4.02 & 74 & 41 & 12.7 & 57 & 77 & 109 & 1.50 \\
\hline W. E. S. & 2.30 & 35 & 1.62 & 42 & 3.22 & 49 & 28 & 11.8 & 58 & 72 & 104 & 1.36 \\
\hline R. S. & 1.41 & 33 & 1.49 & 34 & 2.57 & 33 & 29 & 5.0 & 25 & 96 & 120 & ND $\ddagger$ \\
\hline J. K. S. & 3.42 & 65 & 2.91 & 85 & 4.70 & 68 & 27 & 8.3 & 30 & 91 & 123 & ND \\
\hline W. L. S. & 3.32 & 78 & 1.91 & 53 & 4.32 & 67 & 24 & 14.8 & 60 & 32 & 114 & 0.82 \\
\hline B. T. & 1.62 & 48 & 1.77 & 62 & 3.56 & 50 & 37 & 14.4 & 96 & 85 & 112 & 1.14 \\
\hline Mean & 2.67 & 56.0 & 2.10 & 60.4 & 3.93 & 59.8 & 31.8 & 11.7 & 52.7 & 82.4 & 110.0 & 1.54 \\
\hline$\pm \mathrm{SEM}$ & \pm 0.21 & \pm 3.7 & \pm 0.14 & \pm 2.9 & \pm .27 & \pm 3.2 & \pm 1.7 & \pm 0.8 & \pm 4.2 & \pm 2.1 & \pm 2.1 & \pm 0.17 \\
\hline
\end{tabular}

* Single-breath carbon monoxide diffusing capacity.

$\$$ ND, not done.

with the overall estimate of small airways diameter, 11 had "narrowed" airways and 6 had "not narrowed" airways. The overall estimate of small airway diameter did not correlate with age, sex, smoking history, dura- tion of symptoms, drugs (on or off anti-inflammatory medications), lung volumes (VC, FRC, TLC), or diffusing capacity (Tables IV, V). There was, however, a significant association between RV/TLC and the over-

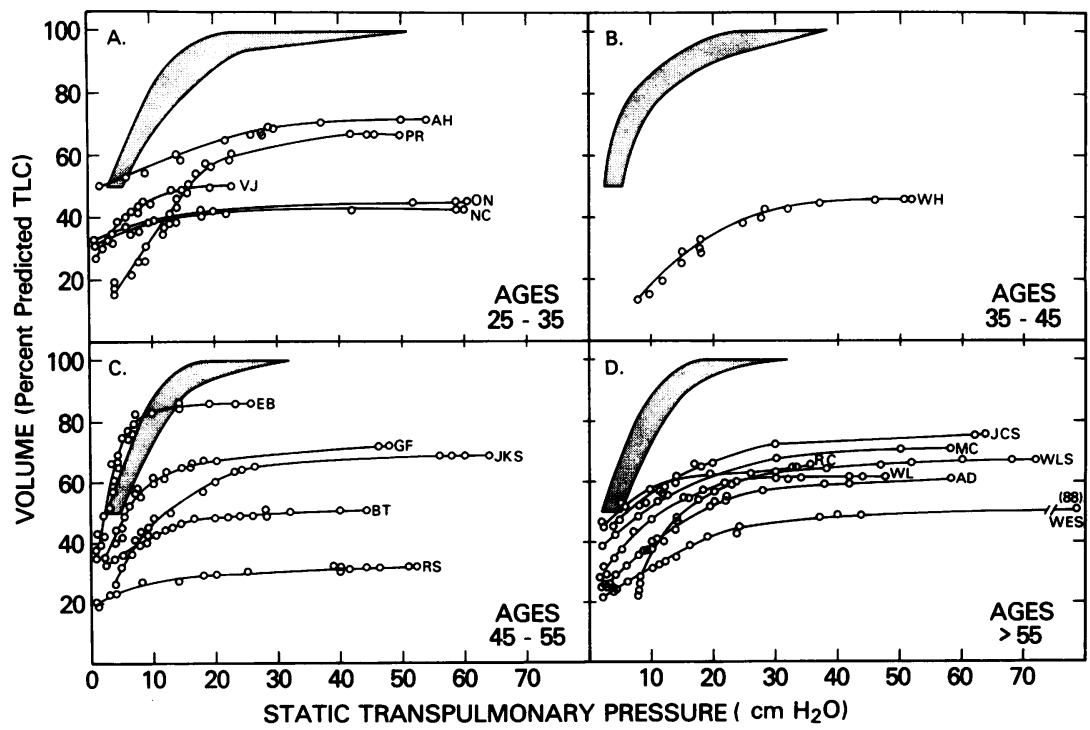

FIGURE 2 Static deflation volume-pressure curves for 18 patients with IPF grouped by age. Lung volume is expressed as percent predicted TLC. Pst is expressed in $\mathrm{cm} \mathrm{H}_{2} \mathrm{O}$. Shaded area is the normal range established by Turner et al. (32). 


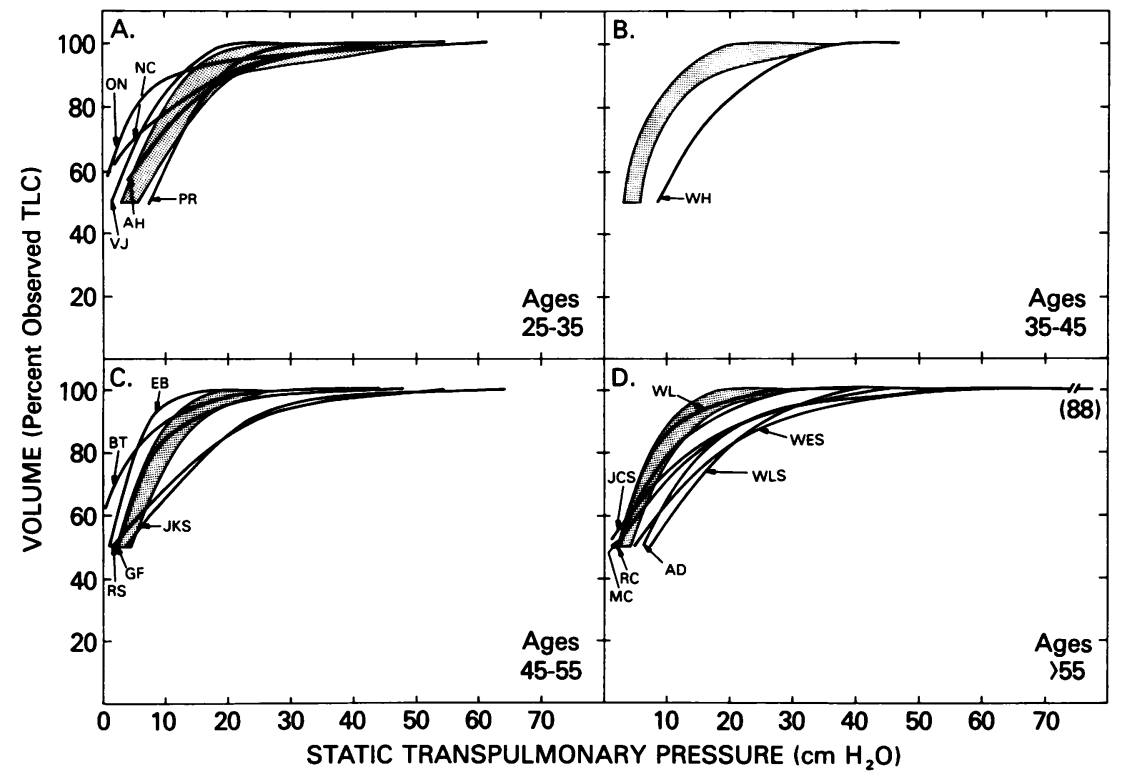

FIGURE 3 Static deflation volume-pressure curves for 18 patients with IPF grouped by age. Lung volume is expressed as percentage of observed (measured) TLC. Pst is expressed in $\mathrm{cm} \mathrm{H}_{2} \mathrm{O}$. Shaded area is the normal range established by Turner et al. (32).

all estimate of small airways diameter whether the comparison was done by Spearman rank correlation $(P=0.017$, Table IV) or Student's $t$ test $(P=0.046$, Table V). In general, patients with narrowed airways had elevated RV/TLC; in no case was an increased
RV/TLC ( $>30 \%$ observed) associated with small airways whose overall status were not narrowed.

By entrance criteria for the study, all patients had normal $\mathrm{FEV}_{1} \%$ and Raw, and thus there was no possible correlation between these monitors of large and

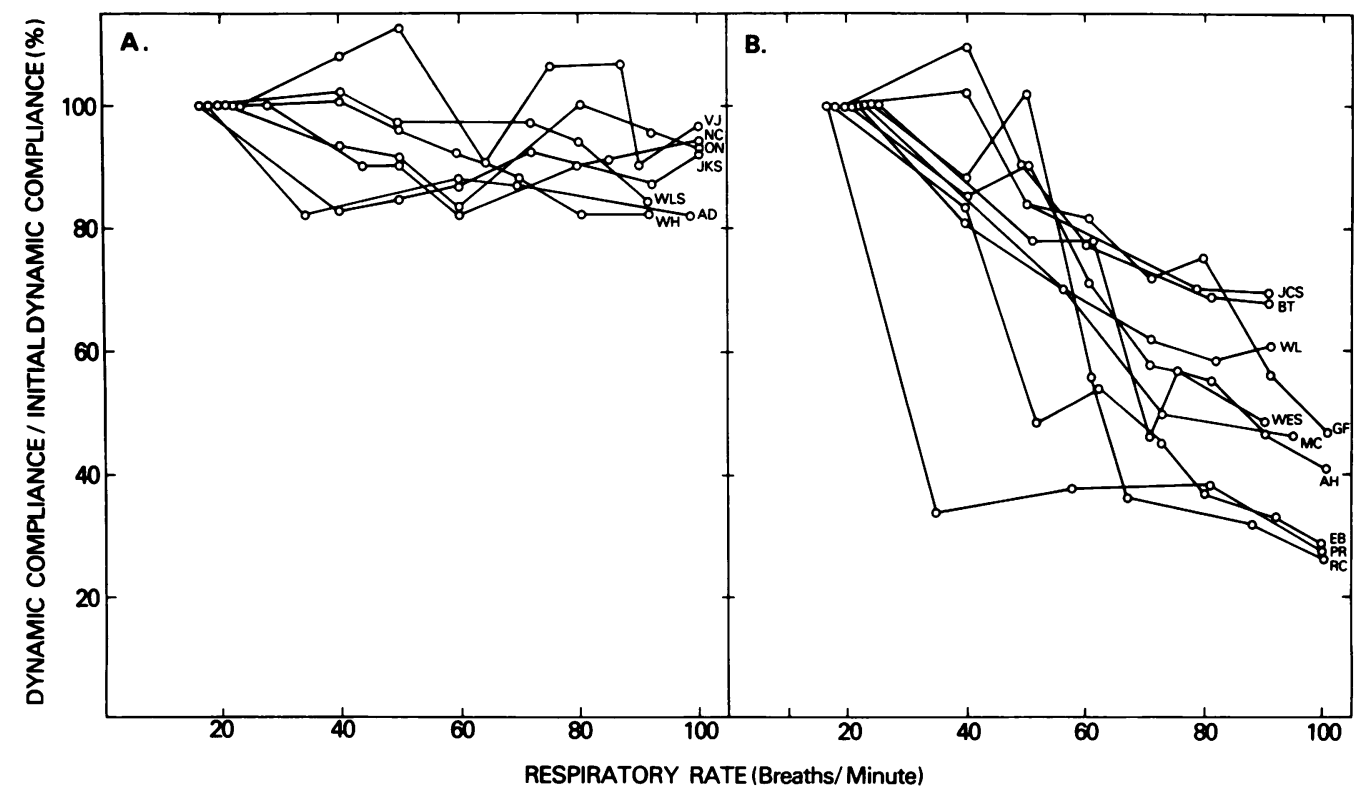

FIGURE 4 Cdyn in 17 patients with IPF expressed as a percentage of initial Cdyn. Respiratory rate is in breaths per minute. A. In seven patients Cdyn was independent of frequency. B. In 10 patients Cdyn was frequency dependent. 


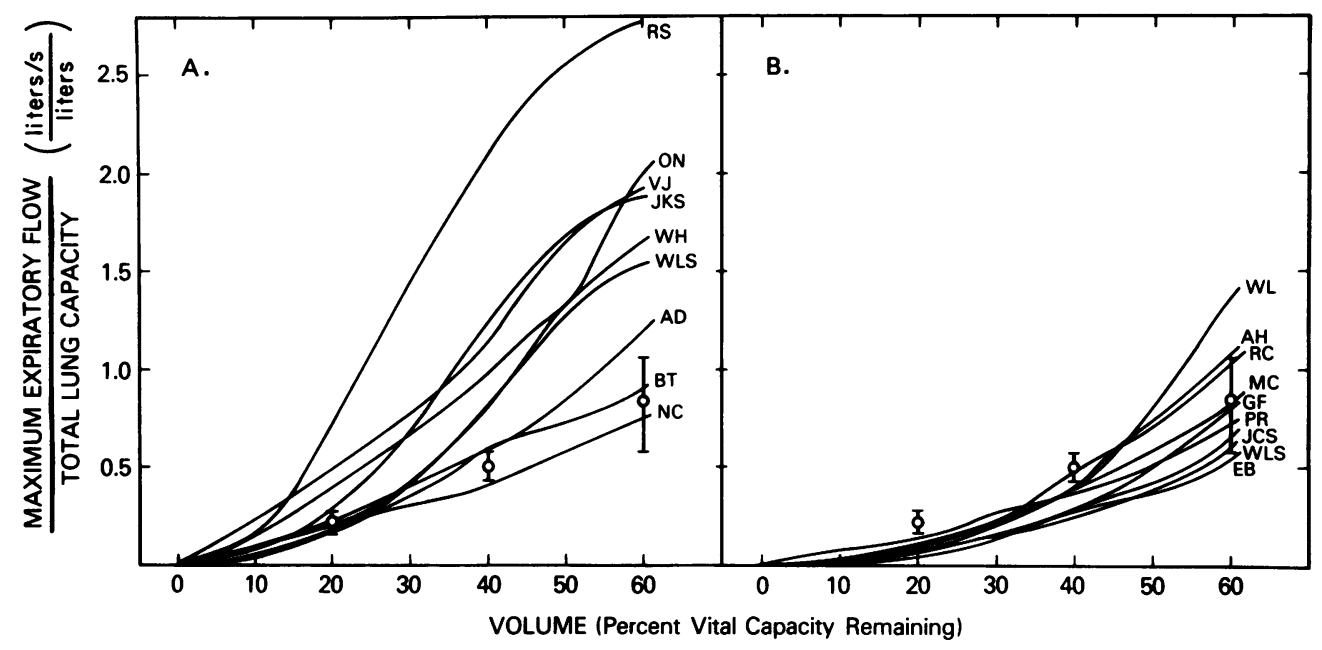

FIGURE 5 MEFV curves of 18 patients with IPF. Flow is expressed in liters per second/observed TLC; volume is expressed as percent VC remaining (60-0\%). Open circles with error bars are the mean \pm SEM established by Gelb et al. (29).

medium airways and the morphologic evidence of narrowed small airways. In comparison, two of the physiologic tests of small airways function (Cdyn, MEFV curves) could predict the overall estimate of small airways diameter in open lung biopsy specimens.

Cdyn was the most sensitive predictor of the diameter of small airways $(P=0.001$, Table VI $) ; 9$ of the 10 patients in whom airways were narrowed had frequency-dependent Cdyn and all 6 patients with not narrowed airways had normal Cdyn. Only one patient who had narrowed airways exhibited normal Cdyn; in no case was Cdyn frequency dependent in a patient who had airways of normal diameter.

The next most sensitive predictor of small airways diameter was the MEFV curve $(P=0.009$, Table
VI). 8 of the 11 patients in whom airways were narrowed had abnormal MEFV curves, whereas all 6 patients in whom airways were considered not narrowed had normal MEFV curves. However, three patients with narrowed small airways had normal MEFV curves. Like Cdyn, in no case was the MEFV curve abnormal in a patient who had airways that were considered not narrowed.

The third physiologic monitor of small airways, the MFSR relationship, was abnormal in 7 of the 11 patients with narrowed airways, and normal in all 6 patients with airways that were not narrowed (Table VI). However, four patients with narrowed airways had MFSR curves within the normal range. Like the other monitors of small airways, the MFSR curve was never

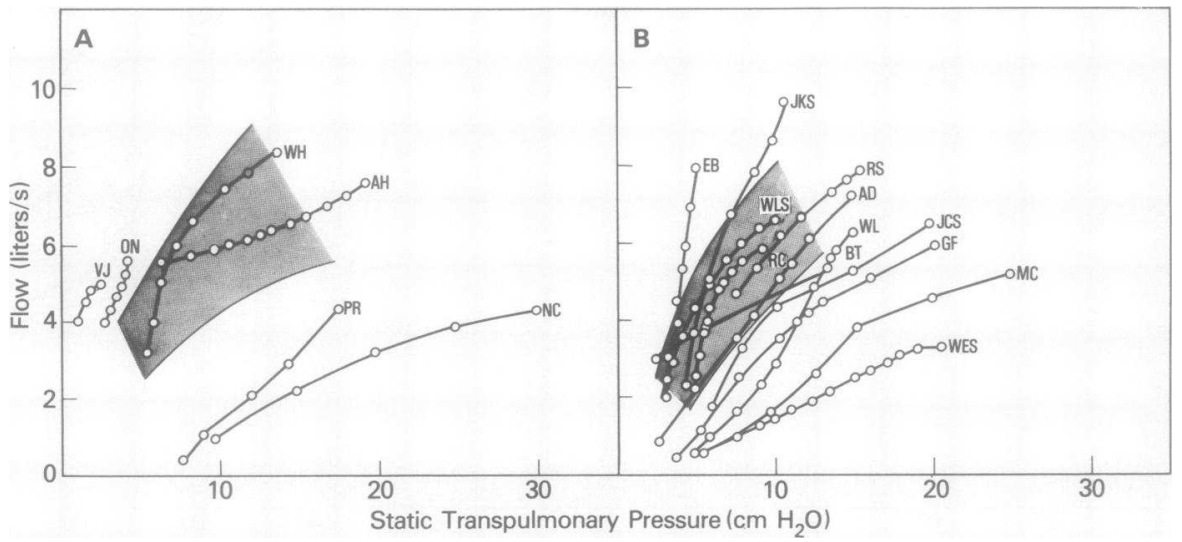

FIGURE 6 MRSR curves in 18 patients with IPF grouped by age. Flow is expressed in liters/second and Pst is expressed in $\mathrm{cm}_{2} \mathrm{O}$. The shaded normal range is derived by plotting $\dot{\mathrm{V}}_{\max }$ predicted by the data of Cherniack and Raber (37) against Pst at the same lung volume predicted by the data of Turner et al. (32). 
TABLE IV

Comparison of Clinical and Standard Physiologic Studies with the Overall Estimate of Small Airways

Diameter of Patients with IPF

\begin{tabular}{lrr}
\hline \multicolumn{1}{c}{ Comparison $^{*}$} & $r$ value & $P$ value \\
\hline Clinical datał vs. overall estimate of small & & \\
airways diameter $\$$ & & \\
Age & 0.139 & 0.601 \\
Sex & 0.030 & 0.904 \\
Smoking history & -0.052 & 0.836 \\
Duration of symptoms & 0.144 & 0.588 \\
Drugs & -0.044 & 0.862 \\
Standard physiologic studies" vs. overall & & \\
estimate of small airways diameter $\$$ & & \\
VC & 0.013 & 0.961 \\
FRC & 0.126 & 0.635 \\
TLC & 0.277 & 0.282 \\
RV/TLC & 0.568 & 0.017 \\
Diffusing capacity & -0.050 & 0.842 \\
\hline
\end{tabular}

* Comparison is by Spearman rank correlation.

$\$$ Data from Table I.

$\S$ Data from Table II.

"Data from Table III.

abnormal in a patient whose airways were considered not narrowed. Even so, the lack of a significant association between the MFSR curve and the overall estimate of small airways diameter suggested that the MFSR curve is not as sensitive as Cdyn or the MEFV curve in detecting narrowed small airways in patients with IPF.

There was no significant correlation between age, sex, smoking history, duration of symptoms, VC, FRC, RV/TLC, $\mathrm{D}_{\mathrm{LCO}}$, and the physiologic monitors of small airways (Table VII). However, there was a significant negative correlation between TLC and Cdyn and between TLC and the MEFV curves; patients with smaller total lung capacities tended to have normal Cdyn and normal MEFV curves, whereas those with larger total lung capacities tended to have frequencydependent Cdyn and abnormal MEFV curves.

Although comparison of the physiologic data with the overall estimate of small airways diameter suggests that RV/TLC (Tables IV, V), Cdyn, and MEFV curves (Table VI) can predict narrowed small airways, only the results of the MEFV curves correlated with the results of Cdyn (the most sensitive predictor of the overall estimate of small airways diameter, Table VIII), suggesting a divergence in the physiologic functions monitored by some of these tests.

\section{DISCUSSION}

Although narrowing and stenosis of small airways were noted in the original description of IPF by Hamman
TABLE V

Comparison of Standard Physiologic Studies between Groups of Patients with Overall Estimate of Small Airways that are Narrowed to Groups of Patients with Overall Estimate of Small Airways that Are Not Narrowed

\begin{tabular}{|c|c|c|c|}
\hline \multirow[b]{2}{*}{$\begin{array}{l}\text { Physiologic } \\
\text { parameter }\end{array}$} & \multicolumn{2}{|c|}{$\begin{array}{l}\text { Mean value of physiologic parameter } \\
\text { in each group of patients* }\end{array}$} & \multirow[b]{2}{*}{$P$ value } \\
\hline & $\begin{array}{l}\text { Those with airways } \\
\text { that are narrowed } t\end{array}$ & $\begin{array}{l}\text { Those with airways that } \\
\text { are not narrowed } \downarrow\end{array}$ & \\
\hline VC & 58.1 & 59.7 & 0.750 \\
\hline TLC & 61.6 & 55.8 & 0.480 \\
\hline FRC & 60.8 & 59.7 & 0.870 \\
\hline RV/TLC & 35.5 & 28.2 & 0.046 \\
\hline $\begin{array}{l}\text { Diffusing } \\
\text { capacity }\end{array}$ & 53.4 & 43.2 & 0.980 \\
\hline
\end{tabular}

* Data from Table III; percent predicted values are used for all physiologic parameters except RV/TLC for which percent observed is used.

\$ Grouped according to the overall estimate of small airway diameter; see Table II.

$\S$ Two-tailed Student's $t$ test.

and Rich (1), subsequent morphologic reports have largely concentrated on the alveoli and alveolar interstitium $(3,4,8-10,13)$; perhaps because the significance of small airways abnormalities in the pathophysiology of some chronic pulmonary disorders has only recently been recognized $(42,43)$. The data presented in this investigation indicate that morphologic and physiologic abnormalities of small airways are present

\section{TABLE VI}

Comparison between the Physiologic Monitors of Small Airways and the Overall Estimate of Small Airways Diameter in Patients with IPF

\begin{tabular}{|c|c|c|c|c|c|}
\hline \multirow[b]{2}{*}{$\begin{array}{l}\text { Physiologic } \\
\text { study }\end{array}$} & \multirow[b]{2}{*}{ Results* } & \multirow{2}{*}{$\begin{array}{l}\text { Number } \\
\text { of } \\
\text { patients }\end{array}$} & \multicolumn{2}{|c|}{$\begin{array}{c}\text { Overall estimate } \\
\text { of small airways } \\
\text { diameter }\end{array}$} & \multirow[b]{2}{*}{$\begin{array}{c}P \\
\text { value } \S\end{array}$} \\
\hline & & & $\begin{array}{l}\text { Nar- } \\
\text { rowed }\end{array}$ & $\begin{array}{l}\text { Not nar- } \\
\text { rowed }\end{array}$ & \\
\hline \multirow[t]{2}{*}{ Cdyn } & Normal & 7 & 1 & 6 & \multirow[t]{2}{*}{0.001} \\
\hline & Abnormal & $9^{\prime \prime}$ & 9 & 0 & \\
\hline \multirow[t]{2}{*}{ MEFV curve } & Normal & 9 & 3 & 6 & \multirow[t]{2}{*}{0.009} \\
\hline & Abnormal & $8^{\prime \prime}$ & 8 & 0 & \\
\hline \multirow[t]{2}{*}{ MFSR curve } & Normal & $10^{\prime \prime}$ & 4 & 6 & \multirow[t]{2}{*}{0.100} \\
\hline & Abnormal & 7 & 7 & 0 & \\
\hline
\end{tabular}

* Data from Figs. 4-6.

\$ Data from Table II.

$\S$ Fisher's exact test.

"One patient (R. C.) was not included in the statistical analysis because the biopsy showed only one airway. 
TABLE VII

Comparison of the Clinical Data and Standard Physiologic Studies with the Physiologic Monitors of Small Airways in Patients with IPF

\begin{tabular}{|c|c|c|c|c|c|c|}
\hline & \multicolumn{6}{|c|}{ Physiologic monitors of small airways* } \\
\hline & \multicolumn{2}{|c|}{ Cdyn } & \multicolumn{2}{|c|}{ MEFV curve } & \multicolumn{2}{|c|}{ MFSR } \\
\hline & $r$ value $\S$ & $P$ value $\S$ & $r$ valụe & $P$ value $\$$ & $r$ value $\$$ & $P$ value \\
\hline \multicolumn{7}{|l|}{ Clinical data $\$$} \\
\hline Age & 0.274 & 0.305 & 0.253 & 0.328 & 0.106 & 0.689 \\
\hline Sex & 0.163 & 0.553 & 0.044 & 0.862 & 0.0635 & 0.803 \\
\hline Smoking history & 0.042 & 0.870 & 0.250 & 0.665 & 0.219 & 0.598 \\
\hline Duration of symptoms & 0.028 & 0.914 & 0.063 & 0.806 & 0.274 & 0.288 \\
\hline \multicolumn{7}{|c|}{ Standard physiologic studies" } \\
\hline $\mathrm{VC}$ & -0.3011 & 0.256 & -0.047 & 0.055 & -0.237 & 0.639 \\
\hline TLC & -0.5611 & 0.023 & -0.663 & 0.004 & -0.066 & 0.797 \\
\hline FRC & -0.261 & 0.332 & 0.289 & 0.259 & -0.132 & 0.619 \\
\hline RV/TLC & -0.371 & 0.156 & -0.266 & 0.303 & -0.371 & 0.140 \\
\hline Diffusing capacity & -0.151 & 0.584 & -0.217 & 0.592 & -0.184 & 0.515 \\
\hline
\end{tabular}

* Data from Figs. 4-6.

\$ Data from Table I.

$\S$ Comparisons made using Spearman rank correlation.

"Data from Table III.

in IPF. The patients studied were representative of patients with IPF; the duration of symptoms and lung biopsy were typical of patients in mid-course (3-13). None had morphologic flndings consistent with "end stage" lung (44).

Morphologic evaluation of small airways in IPF. Only one patient had completely normal airways; in the remainder, the majority of the small airways had

\section{TABLE VIII}

Comparison of the Results of RV/TLC, MEFV Curve, and MFSR Curve with the Results of Cdyn in Patients with IPF

\begin{tabular}{|c|c|c|c|c|c|}
\hline \multirow[b]{2}{*}{$\begin{array}{l}\text { Physiologic } \\
\text { study }\end{array}$} & \multirow[b]{2}{*}{ Results } & \multirow{2}{*}{$\begin{array}{l}\text { Number } \\
\text { of } \\
\text { patients }\end{array}$} & \multicolumn{2}{|c|}{ Cdyn* } & \multirow[b]{2}{*}{$\begin{array}{c}P \\
\text { valuet }\end{array}$} \\
\hline & & & $\begin{array}{l}\text { Nor- } \\
\text { mal }\end{array}$ & $\begin{array}{c}\mathrm{Ab}- \\
\text { normal }\end{array}$ & \\
\hline \multirow[t]{2}{*}{ RV/TLC*\$ } & Normal & 10 & 4 & 6 & \multirow[t]{2}{*}{0.500} \\
\hline & Abnormal & $7^{\prime \prime}$ & 2 & 5 & \\
\hline \multirow[t]{2}{*}{ MEFV curvef } & Normal & $8^{\prime \prime}$ & 7 & 1 & \multirow[t]{2}{*}{0.001} \\
\hline & Abnormal & 9 & 0 & 9 & \\
\hline \multirow[t]{2}{*}{ MFSR curve** } & Normal & $10^{\prime \prime}$ & 6 & 4 & \multirow[t]{2}{*}{0.310} \\
\hline & Abnormal & 7 & 1 & 6 & \\
\hline
\end{tabular}

* Data from Fig. 4.

¥ Fisher's exact test.

$\S$ Data from Table III.

"One patient (R. S.) was excluded because he was unable to do Cdyn.

II Data from Fig. 5.

** Data from Fig. 6. peribronchiolar fibrosis or peribronchiolar inflammation or both; a smaller number of airways had coexisting bronchiolitis. Our data base does not allow for definitive conclusions as to whether these abnormalities are part of the same process that involves the alveolar interstitium; however, the localization of most of the airway pathology in the peribronchiolar tissue suggests that the inflammation and fibrosis of the small airways is secondary to the interstitial process. The dominant small airways abnormalities (peribronchiolar fibrosis, peribronchiolar inflammation, or both) were observed in all nonsmokers (M. C., R. C., V. J., O. N., R. S., B. T.) and all smokers (E. B., N. C., A. D., G. F., A. H., W. H., W. L., P. R., J. C. S., W. E. S., J. K. S.) except one (W. L. S.; Tables I, II). Thus, even though bronchiolar fibrosis and inflammation have been described in smokers (45-47), the lack of correlation of airway abnormalities and smoking history (Table IV, $P=0.836$ ) suggests smoking was not the causative agent in these patients with IPF. In addition, there was no evidence that the airway abnormalities were secondary to intercurrent infection, because all bacterial, mycobacterial, fungal, and viral cultures of open lung biopsies done at our institution were negative.

Some degree of bronchiolectasis was present in approximately one-fourth of all airways evaluated. Although there is no correlation between the morphologic assessment of the severity of disease and airway diameter, it is our impression that small airways in IPF progress through stages beginning with peribronchiolar inflammation leading to peribronchiolar fibrosis. With progressive fibrosis, it is probable that some air- 
ways stenose, whereas others become distorted and ectatic (44). However, this would be difficult to prove.

Even though almost all of the patients had morphologic abnormalities of small airways, these do not necessarily imply airways dysfunction. If intrinsic small airways abnormalities contribute significantly to airways dysfunction, the feature which should be compared to the physiologic studies is airway diameter (e.g. narrowed or not narrowed). 12 of the 18 patients had an overall estimate of small airways diameter of narrowed; the morphologic data, therefore, suggest that these patients have physiologic alterations consistent with obstruction of small airways.

It may be argued that biopsy specimens are not representative of the disease and that multiple samples, available only at autopsy, are necessary to fully evaluate IPF; or that biopsy specimens present special problems in the evaluation of airways diameter because it is not possible to "physiologically" inflate and fix an open lung biopsy as can be done with postmortem lung. However, it is critical that evaluation of small airways in IPF be done with biopsy (rather than postmortem) material because: (a) patients with IPF often die from a generalized pulmonary infection, a process which in itself may alter the morphology and diameter of small airways; (b) those who die without respiratory infection usually have "end-stage" lung, in which the disease is too far advanced to allow for rational morphologic analysis; and (c) to compare airway morphology with airway function (i.e. with physiologic studies), it is necessary to make the interval between the two as short as possible; a situation which is impossible when relying on postmortem lung.

Thus, to study small airway morphology in IPF in mid-course, it is mandatory that only biopsy material be used. To attempt to minimize errors in estimating airway diameter, detailed diameter grading was not attempted, only categories of narrowed, normal, or dilated were used. In addition, three independent criteria were used to estimate airway diameter; all done without knowledge of the physiologic data. Each method of diameter estimate gave similar results. In addition, to attempt to provide "representative" biopsies, the specimens were taken in areas appearing "average" on the chest roentgenogram.

Physiologic evaluation of small airways in IPF. None of the study patients had evidence of increased resistance to airflow by standard monitors of airway function $\left(\mathrm{FEV}_{1} \%\right.$, Raw $)$. However, a significant number had abnormalities in physiologic tests considered to be monitors of small airways function. $59 \%$ had frequency-dependent Cydn (a decrease in Cdyn/initial Cdyn of greater than $20 \%$ with increasing respiratory rates). The remaining patients had normal Cdyn (a change of no more than $20 \%$ of Cdyn/initial Cdyn at increasing respiratory rates). In addition, $50 \%$ of the patients had abnormal MEFV curves and 39\% had abnormal MEFV curves.

When the Cdyn data were plotted as percent of static compliance (Cstat) as described by Woolcock et al. (56), five of the seven patients (W. H., W. L. S., O. N., N. C., J. C. S.) with normal Cdyn (Fig. 3, group A.) had Cdyn/Cstat of $<80 \%$ at initial breathing frequencies (data not shown). This subgroup of patients did not, however, exhibit a progressive fall in Cdyn with increasing respiratory rates regardless of the method of analysis (Cdyn/initial Cdyn or Cdyn/Cstat). Four of these patients have been restudied at 3-6 mo intervals and exhibit identical reductions in Cdyn/Cstat at initial breathing frequencies without frequency dependence. Reduced Cdyn/Cstat at initial respiratory rates have been previously noted in fibrotic lung disease $(49,50)$. The reason for this is not clear, although alterations in surface forces which result in increased hysteresis are possible (49). In our patients, analysis of physiologic and morphologic data did not reveal significant differences between this subgroup of patients compared to those whose Cdyn/Cstat were $>80 \%$ at initial respiratory rates. The former did, however, tend to have more severe fibrosis.

Other physiologic studies have suggested that patients with IPF have small airways abnormalities. In a study of airway function in pulmonary fibrosis, Ostrow and Cherniack (38) included patients with "cryptogenic fibrosing alveolitis" whose physiologic features were similar to our patients. Like our study group, their patients had normal airway function by standard criteria, yet a significant number had physiologic evidence of increased resistance to airflow in small airways. A similar study by Yernalt et al. (49) also demonstrated that many of these patients have evidence of increased small airways resistance. In contrast, Schofield et al. (51) measured upstream conductance in patients with fibrotic lung disease (three with IPF), and found that these patients had normal upstream conductance. However, it is likely that those patients fall into the group of our patients $(61 \%)$ that also had normal MFSR curves.

Recent studies have suggested that closing volume and closing capacity might be useful monitors of small airways in fibrotic lung disease $(52,53)$. In our group of 18 patients, we have performed more than 200 determinations of closing volume and closing capacity using the methods of Buist and Ross $(54,55)$. These tests were quite variable, even when performed on the same patient on consecutive days of the same hospitalization (data not shown). Thus, we do not find these to be useful in patients with IPF. Although closing volume and closing capacity may be useful for the detection of small airways abnormalities in patients with normal elastic recoil, they are less useful when recoil is increased as in patients with IPF. In addition, al- 
though the phase III data of the single breath nitrogen test was highly reproducible in these patients, there was no correlation between the slope of phase III $\left(\Delta \mathrm{N}_{2} /\right.$ liter $)$ and any of the clinical, physiologic or morphologic parameters under study.

Comparison of clinical, physiologic, and morphologic data in IPF. Although it is generally accepted that MFSR curves can detect airflow obstruction in the presence of increased elastic recoil (48), it must be remembered that the use of Cdyn and MEFV curves as monitors of small airways function has been established only in the presence of normal lung resistance and normal elastic recoil (56-58). Inasmuch as patients with IPF have elevations of both $(50,59)$, it is possible that these physiologic abnormalities are secondary to alterations in regional compliance produced by the alveolar disease. To establish the valid use of these studies in IPF, it is necessary to demonstrate an association between these monitors of small airways function and the actual morphologic evidence of narrowed small airways.

The correlative data (Table VI) strongly suggest that Cdyn and MEFV curves detect, with a high degree of reliability, which patients with IPF have narrowed airways and which have not narrowed airways. These statistical comparisons are important because it could be argued that because both Cdyn and MEFV curves detect alterations in mechanical (resistance $\times$ compliance) time constants $(56-58,60)$, it is possible that abnormalities in these tests reflect abnormalities in regional compliance as well as airway resistance. However, if regional compliance abnormalities alone were responsible for making these tests abnormal in IPF, we would expect the results of Cdyn and MEFV curves to be randomly distributed, rather than yielding significant correlations with the morphologic estimates of small airways diameter. In addition, if volume pressure data are plotted with volume expressed as a percentage of measured TLC (Fig. 3) as Gibson and Pride have suggested (61), five patients who exhibited frequency-dependent Cdyn have curves which are similar to normals. This would suggest that there is uniform involvement of parenchyma and would favor the fact that frequency-dependent Cdyn is related to airways disease.

Even though $39 \%$ of the patients had abnormal MFSR curves, these data did not correlate with the morphologic assessment of airway narrowing $(P=0.10$, Table VI). This lack of significant correlation occurred because although patients with not narrowed airways always had a normal MFSR curve, 4 of the 11 patients with narrowed airways also had normal MFSR studies. Thus, of the three physiologic methods (Cdyn, MEFV, MFSR) used in this study to test small airway function, the MFSR curve is the least sensitive. This may be due to the complexity of the volume-pressure curve in this disease, particularly at low lung volumes. Although almost all of our patients had increased elastic recoil near TLC, some had reduced recoil near FRC (Fig. 2 and 3). Similar volume-pressure curves were observed by Ostrow and Cherniack (38) and Yernalt et al. (49). The reduction in elastic recoil near FRC may result from a multitude of factors (e.g. rearrangements of connective tissue, increased tissue rigidity, destructive lesions), all of which may modify the usefulness of relying on measurement of upstream resistance as a monitor of small airways narrowing in IPF.

In comparison to Cdyn and MEFV curves, there were no significant associations among VC, FRC, and $\mathrm{D}_{\mathrm{LCO}}$, and the overall estimate of small airways diameter. Even though TLC correlated significantly with Cdyn and MEFV curves (Table VII), there was no correlation between TLC and overall estimate of small airways diameter. Thus, TLC cannot be used as a predictor of small airways disease in these patients. There was, however, a significant association between RV/TLC and airways diameter, suggesting that narrowing of small airways may account for the commonly observed increased RV/TLC seen in IPF $(6,7,16)$. Although statistically significant, there was only a small difference in RV/TLC between patients grouped according to the estimate of airways diameter. Therefore, we do not believe that RV/TLC is a predictor of small airways diameter in IPF.

If we use frequency dependency of Cdyn as the best criterion for small airways dysfunction in IPF (Cdyn correlates best with the overall estimates of airway diameter, Table VI), it is interesting to note that results of MEFV curves correlate well with Cdyn, but the MFSR and RV/TLC results do not (Table VIII). These results are similar to that found by Martin et al. (62) and Gelb et al. (57) in evaluating these studies for use in patients with isolated small airways disease. Thus, Cdyn remains as the most sensitive and valid monitor of small airways disease, even in disorders as diverse as asthma (63) and IPF.

Inasmuch as age, sex, duration of symptoms, drugs, and smoking history could possibly modulate small airways disease, it was important to determine whether there were associations between these parameters and the morphologic assessment of small airways diameter or the physiologic monitors of small airways function. However, no significant correlates were found (Tables IV, V, VII).

Significance of small airways disease in IPF. The demonstration of morphologic and physiologic evidence of small airways abnormalities in IPF may have significant clinical implications. First, the detection of small airways dysfunction in IPF may be useful for staging this disease. Second, the hypoxemia may be, in part, secondary to ventilation-perfusion mismatching resulting from increased resistance to airflow in 
small airways. In our patient group, a small number of patients under therapy have demonstrated improvement of small airways function with lessening of hypoxemia with exercise. Thus, as suggested by Ostrow and Cherniack (38), small airways dysfunction may respond to therapeutic intervention which may significantly improve the level of oxygenation of patients with IPF.

\section{ACKNOWLEDGMENTS}

We thank Doctors Norton Elson and Byron McLees for their advice; Dr. David DeMetts for his help with the statistical analysis; Edwyna von Gal and Filippina Giacometti for their expert technical assistance; and Kirsten Cook and Nancy Wyne for their editorial assistance.

\section{REFERENCES}

1. Hamman, L., and A. R. Rich. 1944. Acute diffuse interstitial fibrosis of the lungs. Bull. Johns Hopkins Hosp. 74: $177-212$.

2. Rubin, E. H., and R. Lubliner. 1957. The Hamman-Rich syndrome: review of the literature and analysis of 15 cases. Medicine (Baltimore). 36: 397-463.

3. Anderson, A. E., Jr., and A. G. Foraker. 1960. Morphological aspects of interstitial pulmonary fibrosis. Arch. Pathol. 70: 79-93.

4. Scadding, J. G. 1960. Chronic diffuse interstitial fibrosis of the lungs. Br. Med. J. 1: 443-450.

5. Herbert, F. A., B. B. Nahmias, E. A. Gaensler, and H. E. MacMahon. 1962. Pathophysiology of interstitial pulmonary fibrosis: report of 19 cases and follow-up with corticosteroids. Arch. Intern. Med. 110: 628-648.

6. Livingstone, J. L., J. G. Lewis, L. Reid, and K. E. Jefferson. 1964. Diffuse interstitial pulmonary fibrosis: clinical, radiological, and pathological study based on 45 patients. Q. J. Med. 33: 71-103.

7. Marks, A. 1967. Diffuse interstitial pulmonary fibrosis. Med. Clin. North Am. 51: 439-457.

8. Scadding, J. G., and K. F. W. Hinson. 1967. Diffuse fibrosing alveolitis (diffuse interstitial fibrosis of the lungs): correlation of histology at biopsy with prognosis. Thorax. 22: 291-304.

9. Liebow, A. A., and C. B. Carrington. 1967. Alveolar diseases: the interstitial pneumonias. In Frontiers of Pulmonary Radiology. M. Simon, E. J. Potchen, and M. LeMay, editors. Grune \& Stratton, Inc., New York. 102141.

10. Liebow, A. A. 1968. New concepts and entities in pulmonary disease. In The Lung. A. A. Liebow and D. E. Smith, editors. Williams and Wilkins, Baltimore. 332-365.

11. DeRemee, R. A., E. G. Harrison, Jr., and H. A. Andersen. 1972. The concept of classical interstitial pneumonitis-fibrosis (CIP-F) as a clinicopathologic syndrome. Chest. 61: 213-220.

12. Stack, B. H. R., Y. F. J. Choo-Kang, and B. E. Heard. 1972. The prognosis of cryptogenic fibrosing alveolitis. Thorax. 27: 535-542.

13. Scadding, J. G. 1974. Diffuse alveolar pulmonary fibrosis. Thorax. 29: 271-281.

14. Kravis, T. C., A. Ahmed, T. E. Brown, J. D. Fulmer, and R. G. Crystal. 1976. Pathogenic mechanisms in pulmonary fibrosis: collagen-induced migration inhibition factor production and cytotoxicity mediated by lymphocytes. $J$. Clin. Invest. 58: 1223-1232.
15. Reynolds, H. Y., J. D. Fulmer, J. A. Kazmierowski, W. C. Roberts, M. M. Frank, and R. G. Crystal. 1977. Analysis of cellular and protein content of broncho-alveolar lavage fluid from patients with idiopathic pulmonary fibrosis and chronic hypersensitivity pneumonitis. J. Clin Invest. 59: 165- 175.

16. Crystal, R. G., J. D. Fulmer, W. C. Roberts, M. L. Moss, B. R. Line, and H. Y. Reynolds. 1976. Idiopathic pulmonary fibrosis: clinical, histologic, radiographic, physiologic, scintigraphic, cytological, and biochemical aspects. Ann. Intern. Med 85: 769-788.

17. Austrian, R., J. H. McClement, A. D. Renzetti, Jr., K. W. Donald, R. L. Riley, and A. Cournand. 1951. Clinical and physiologic features of some types of pulmonary diseases with impairment of alveolar-capillalry diffusion: the syndrome of "alveolar-capillary block." Am. J. Med. 11: $667-685$.

18. Finley, T. N., E. W. Swenson, and J. H. Comroe, Jr. 1962. The cause of arterial hypoxemia at rest in patients with “alveolar-capillary block syndrome." J. Clin. Invest. 41: 618-622.

19. Wagner, P. D., D. R. Dantzker, R. Dueck, J. L. DePolo, K. Wasserman, and J. B. West. 1976. Distribution of ventilation-perfusion ratios in patients with interstitial lung disease. Chest. 69(Suppl.): 256-257.

20. McFadden, E. R., Jr., and H. A. Lyons. 1968. Airway resistance and uneven ventilation in bronchial asthma. $J$. Appl. Physiol. 25: 365-370.

21. Heckscher, T., H. Bass, A. Oriol, B. Rose, N. R. Anthonisen, and D. V. Bates. 1968. Regional lung function in patients with bronchial asthma. J. Clin. Invest. 47: 1063-1070.

22. Meneely, G. R., and N. L. Kaltreider. 1949. The volume of the lung determined by helium dilution: description of method and comparison with other procedures. J. Clin. Invest. 28: 129-139.

23. Morris, J. F., A. Koski, and L. C. Johnson. 1971. Spirometric standards for healthy nonsmoking adults. Am. Rev. Respir. Dis. 103: 57-67.

24. Goldman, H. I., and M. R. Becklake. 1959. Respiratory function tests: normal values at medium altitudes and the predicition of normal results. Am. Rev. Tuberc. Pulm. Dis. 79: 457-467.

25. Macdonald, J. B., T. J. Cole, and A. Seaton. 1975. Forced expiratory time-its reliability as a lung function test. Thorax. 30: 554-559.

26. Ogilvie, C. M., R. E. Forster, W. S. Blakemore, and J. W. Morton. 1957. A standard breath holding technique for the clinical measurement of the diffusing capacity of the lung for carbon monoxide. J. Clin. Invest. 36: 1-17.

27. Gaensler, E. A., and G. W. Wright. 1966. Evaluation of respiratory impairment. Arch. Environ. Health 12: 146189.

28. Dubois, A. B., S. Y. Botelho, and J. H. Comroe, Jr. 1956. A new method for measuring airway resistance in man using a body plethysmograph: values in normal subjects and in patients with respiratory disease. J. Clin. Invest. 35: 327-335.

29. Gelb, A. F., W. M. Gold, R. R. Wright, H. R. Bruch, and J. A. Nadel. 1973. Physiologic diagnosis of subclinical emphysema. Am. Rev. Respir. Dis. 107: 50-63.

30. Milic-Emili, J., J. Mead, J. M. Turner, and E. M. Glauser. 1964. Improved technique for estimating pleural pressure from eosphageal balloons. J. Appl. Physiol. 19: 207-211.

31. Lemen, R., M. Benson, and J. G. Jones. 1974. Absolute pressure measurements with hand-dipped and manufactured esophageal balloons. J. Appl. Physiol. 37: 600603. 
32. Turner, J. M., J. Mead, and M. E. Wohl. 1968. Elasticity of human lungs in relation to age. J. Appl. Physiol. 25: $664-671$.

33. Hyatt, R. E., D. P. Schilder, and D. L. Fry. 1958. Relationship between maximum expiratory flow and the degree of lung inflation. J. Appl. Physiol. 13: 331-336.

34. Seaton, Anthony, N. LeRoy Lapp, and W. K. C. Morgan. 1972. Lung mechanics and frequency dependence of compliance in coal miners. J. Clin. Invest. 51: 1203-1211.

35. Blair, H. Thomas, S. B. Greenberg, P. M. Stevens, P. A. Bilunos, and R. B. Couch. 1976. Effects of rhinovirus infection on pulmonary function of healthy human volunteers. Am. Rev. Respir. Dis. 114: 95-102.

36. Mead, J., J. M. Turner, P. T. Macklem, and J. B. Little. 1967. Significance of the relationship between lung recoil and maximum expiratory flow. J. Appl. Physiol. 22: 95-108.

37. Cherniack, R. M., and M. B. Raber. 1972. Normal standards for ventilatory function using an automated wedge spirometer. Am. Rev. Respir. Dis. 106: 38-46.

38. Ostrow, D., and R. M. Cherniack. 1973. Resistance to airflow in patients with diffuse interstitial lung disease. Am. Rev. Respir. Dis. 108: 205-210.

39. Snedecor, G. W., and W. G. Cochran. 1967. Statistical Methods. Iowa State University Press, Ames, Iowa. 6th edition. 194.

40. Snedecor, G. W., and W. G. Cochran. 1967. Statistical Methods. Iowa State University Press, Ames, Iowa. 6th edition. 59-61.

41. Brownlee, K. A. 1960. Statistical Theory and Methodology in Science and Engineering. John Wiley \& Sons, Inc., New York. 123-125.

42. Hogg, J. C., P. T. Macklem, and W. M. Thurlbeck. 1968. Site and nature of airway obstruction in chronic obstructive lung disease.N. Engl.J. Med. 278: 1355-1360.

43. Despas, P. J., M. Leroux, and P. T. Macklem. 1972. Site of airway obstruction in asthma as determined by measuring maximal expiratory flow breathing air and a helium-oxygen mixture. J. Clin. Invest. 51: 3235-3243.

44. Heppleston, A. G. 1956. The pathology of honeycomb lung. Thorax. 11: 77-93.

45. Niewoehner, D. E., J. Kleinerman, and D. B. Rice. 1974. Pathological changes in the peripheral airways of young cigarette smokers. N. Engl. J. Med. 291: 755-758.

46. Thurlbeck, W. M. 1973. Disease of small airways, with particular reference to lesions found in asymptomatic chronic bronchitis without emphysema. Chest. 63 (Suppl.): 70S-71S.

47. Zamel, N., J. Hogg, and A. Gelb. 1976. Mechanisms of maximal expiratory flow limitation in clinically unsuspected emphysema and obstruction of peripheral airways. Am. Rev. Respir. Dis. 113: 337-345.
48. Macklem, P. T. 1975. Tests of lung mechanics. N. Engl. J. Med. 293: 339-342.

49. Yernalt, J. C., M. DeJonghe, A. DeCoster, and M. Englert. 1975. Pulmonary mechanics in diffuse fibrosing alveolitis. Bull. Physio-pathol. Respir. 11: 231-244.

50. Macklem, P. T., and M. R. Becklake. 1963. The relationship between the mechanical and diffusing properties of lung in health and disease. Am. Rev. Respir. Dis. 87: 47-56.

51. Schofield, N. M., R. J. Davies, I. R. Cameron, and M. Green. 1976. Small airways in fibrosing alveolitis. Am. Rev. Respir. Dis. 113: 729-735.

52. Levinson, R. S., L. F. Metzger, N. N. Stanley, J. S. Brody, and N. S. Cherniack. 1973. Airway function in interstitial disease. Am. Rev. Respir. Dis. 107: 1105. (Abstr.)

53. Levinson, R. S., L. F. Metzger, N. N. Stanley, S. G. Kelsen, M. D. Altose, N. S. Cherniack, and J. S. Brody. 1977. Airway function in sarcoidosis. Am. J. Med. 62: 51-59.

54. Buist, A. S., and B. B. Ross. 1973. Predicted values for closing volumes using a modified single breath nitrogen test. Am. Rev. Respir. Dis. 107: 744-752.

55. Buist, A. Sonia. 1975. The single-breath nitrogen test. N. Engl. J. Med. 293: 438-440.

56. Woolcock, A. J., N. J. Vincent, and P. T. Macklem. 1969. Frequency dependence of compliance as a test for obstruction of the small airways. J. Clin. Invest. 48: 1097-1106.

57. Gelb, A. F., and N. Zamel. 1973. Simplified diagnosis of small-airway obstruction. N. Engl. J. Med. 288: 395-398.

58. Gelb, A. F., and B. J. MacAnally. 1973. Early detection of obstructive lung disease by analysis of maximal expiratory flow-volume curve. Chest. 64: 749-753.

59. Bachofen, H., and M. Scherrer. 1967. Lung tissue resistance in diffuse interstitial fibrosis. J. Clin. Invest. 46: $133-140$.

60. Otis, A. B., C. B. McKerrow, R. A. Bartlett, J. Mead, M. B. McIlroy, N. J. Selverstone, and E. P. Radford. 1956. Mechanical factors in distribution of pulmonary ventilation. J. Appl. Physiol. 8: 427-443.

61. Gibson, A. J., and N. B. Pride. 1976. A reappraisal of lung mechanics in fibrosing alveolitis. Chest. 69(Suppl.): 256.

62. Martin, R. R., D. Lindsay, P. Despas. D. Bruce, M. Leroux, N. R. Anthonisen, and P. T. Macklem. 1975. The early detection of airway obstruction. Am. Rev. Respir. Dis. 111: 119-125.

63. Hill, D. J., L. I. Landu, and P. D. Phelan. 1972. Small airway disease in asymptomatic asthmatic adolescents. Am. Rev. Respir. Dis. 106: 873-880. 